Session 1359

\title{
Greenfield Coalition Course Modules in Measurements and Instrumentation
}

\author{
Gregory L. Tonkay, Emory W. Zimmers, Lawrence R. Butler, and \\ Jenny Wang-Chavez \\ Lehigh University/Lehigh University/Butler Engineering and Contracting, \\ Inc., Emmaus, PA/ Greenfield Coalition
}

\begin{abstract}
This paper describes the overall structures and approaches used to develop course materials prepared for the National Science Foundation's Greenfield Coalition. These course modules were developed in the areas of Measurements and Instrumentation. They are intended to fit into the degrees offered at Focus: HOPE and the Greenfield Coalition. They are also intended for dissemination and use by other universities around the world. Joint development with Greenfield Coalition personnel is described using the Enterprise Systems Center Collaboratory at Lehigh University. Two of the interactive activities are described in detail in the paper. The examples chosen include a user interactive flash animation and an Excel file used to illustrate the concepts of digital to analog and analog to digital conversion, respectively.
\end{abstract}

Introduction

Greenfield Coalition is a National Science Foundation supported coalition made up of university partners, industry partners, and Focus: HOPE, a non-profit organization that offers many types of programs to benefit society, including a teaching factory. While most partners are located close to Detroit, Lehigh University is located in Bethlehem, PA. Lehigh has been a partner for 10 years and has tested many educational philosophies related to distance education during that time.

The Greenfield Coalition learning system is predicated on the belief that students will learn faster and will become more effective problem solvers if engineering education and practice are integrated, and students actively participate in their learning ${ }^{1}$. Furthermore, students will benefit in their study of core subjects such as math, physics, and chemistry if they better understand how the material relates to their experience in the factory.

With this in mind, the topics of measurements and instrumentation were pushed to the beginning of the curriculum, before or concurrent with physics and chemistry. Traditionally, the topics of measurements and instrumentation occur later in the curriculum. This means that the material 
covered in these activities must use more basic concepts and not be immersed in complicated mathematics.

The modules were developed for beginning engineering students to understand the basic concepts involved in measuring signals, converting them to a different form and controlling a simple system. Most of the activities developed are accessible from the Internet so students anywhere can have concepts reinforced through computer-based activities. The activities vary from viewing animations to interacting with programs, to working with interactive Excel spreadsheets. The activities are meant to supplement actual laboratory experiences that normally occur in engineering curricula.

\section{Greenfield Coalition Curriculum Approach}

To implement the concepts of experiential learning and allow students to more easily acquire core competencies, Greenfield Coalition developed a unique approach to design course materials. An explanation of this approach and the process used to develop material for the curricula have been previously presented ${ }^{2}$. It should be noted that Greenfield Coalition does not offer any degrees. Instead, partner universities offer the degrees. Greenfield oversees and controls the curricular issues pertaining to the degrees.

Measurements and Instrumentation are each one-credit courses required for each of the degrees: Associate of Science in Manufacturing Engineering and Technology, Bachelor of Manufacturing Engineering, and Bachelor of Science in Manufacturing Engineering Technology. The Measurements course is offered first in a student's education and is followed by Instrumentation. Course details for Instrumentation and Measurements are presented in the following sections.

The reading assignments for these courses are a mixture of handbook articles, catalog articles, and web resources. The basic articles provided in the catalogs by companies such as Omega Corporation are written at a level that entry-level college students can understand. They also provide a low-cost alternative to textbooks. Furthermore, most of the textbooks in these areas are written for college students beyond the second year.

\section{Overview of Measurements Activities}

Measurements is recommended for the first semester students. The terminal objective for Measurements is "Upon completion of the course, the student will be able to define measurement terms and characteristics; select appropriate instruments, sensors, and devices to measure various physical properties; and calculate several example measurements." The modules and sessions of Measurements are listed in Figure 1. 


\begin{tabular}{|l|}
\hline Module 1: Standards \& Instruments \\
- Session 1: Measurement Terms \& Standards \\
- Session 2: Instruments \& Sensors \\
- Session 3: Gages \& Wear Allowance \\
\hline Module 2: Sensors \& Devices \\
- Session 1: Pressure \& Flow \\
- Session 2: Ohm's Law Relationships \\
- Session 3: Temperature \\
- Session 4: Strain
\end{tabular}

Figure 1. Structure of the Measurements course

Students at the CAT (Center for Advanced Technology) at Focus: HOPE are all trained as machinists prior to entering the degree programs, so the focus of the first module is to help students refresh their prior knowledge. They have already used many types of instruments and gages. While they know that there is a wear allowance on gages, they have never calculated the go-nogo gage sizes needed to measure a specific feature. Examples of activities in the first module include animation to differentiate between accuracy and repeatability, graphics of current measurement standards, images and animations of various instruments and sensors, and animation of ring and plug gage wear along with calculations to determine wear allowances for different types of dimensions.

The second module introduces students to sensors and devices used to measure properties they encounter every day in the factory. The material is meant to convey an intuitive understanding of the operation of the sensors rather than a detailed analysis. The purpose is to provide a reference and relevance when they perform studies of the physical phenomenon in physics. In the session on pressure and flow, students interact with animations relating pressure differential to flow within a pipe. They determine that the relationship is non-linear but can still be used to predict one variable given the other. There is also an animation showing the effects on different pressure gages connected to a common tank as the tank moves between regions of different atmospheric pressures.

The Ohm's Law relationships build upon the pressure and flow relationships. Students use a simulated circuit to discover the relationships between voltage, current, and resistance. Video and static images are used in a thermocouple activity. Students learn how to calculate the temperature, given a voltage from a specific thermocouple. Finally, in the session on strain, students build upon the Ohm's Law relationship to determine how strain gages work. An animation depicts the change in cross-sectional area as a wire is strained. This increases the resistance of the wire and relates back to Ohm's Law and how the current or voltage varies.

\section{Overview of Instrumentation Activities}

The Instrumentation course immediately follows Measurements. The terminal objective for Instrumentation is "Upon completion of the course, the student will be able to characterize signal types and develop elementary ladder logic programs for Programmable Logic Controllers (PLCs). The modules and sessions of Instrumentation are listed in Figure 2. 


\begin{tabular}{|l|}
\hline Module 1: Signals \& Conversions \\
- Session 1: Types \& Characteristics of Signals \\
- Session 2: Number System Bases \& Conversions \\
- Session 3: Digital \& Analog Conversions \\
\hline Module 2: Programmable Logic Controllers (PLCs) \\
- Session 1: Elementary Ladder Logic \\
- Session 2: PLC Modules \& Applications \\
\hline
\end{tabular}

Figure 2. Structure of the Instrumentation course

The first module allows students to explore the differences between analog and digital signals and introduces the concept of multiplexing. An Excel spreadsheet allows students to explore the effects of quantization level and sampling rate on the accuracy of sampled signals. They view the analog sine wave as an input and the digital conversion using the levels they choose. Also, they view an animation about time-based multiplexing and the factors that affect signal throughput. The session on number systems and bases includes an animation and Excel spreadsheet for students to learn how to convert between base 2 and base 10. Session 3, digital and analog conversions, is covered in detail in the next section.

The second module focuses on the elementary use and programming of PLCs. The first session uses animation to show how current flows through a ladder logic diagram. Then a PLC simulator is used to build and test a ladder logic program. The second session uses photos to depict the use of PLCs to control various systems.

Detailed Example from Instrumentation Module 1, Session 3

Module 1, Session 3: Digital to Analog Conversions consists of four activities. The first activity is a series of readings and directed questions for the students to consider as they read. To focus the reading the following topics are provided:

- Resolution of D/A and A/D converters

- Digital to Analog Converter Operation

- Time to perform $\mathrm{D} / \mathrm{A}$ conversions as a function of the number of digital bits

- Successive Approximation Analog to Digital Converter Operation

- Time to perform A/D conversions as a function of the number of digital bits

After the readings, the students should be able to answer these directed questions:

- Why does it take longer to perform A/D conversions than D/A conversions?

- Explain the tradeoff between resolution and time of conversion for $\mathrm{A} / \mathrm{D}$ converters that uses successive approximation.

- For 12-bit A/D converters that use successive approximation, how many D/A conversions are required to perform one $\mathrm{A} / \mathrm{D}$ conversion?

The second activity focuses on D to A conversions. The students step through several screens that explain D to A converters. Part of this explanation draws an analogy between current and flow rate of water. An interactive animation is performed. Further details about the animation are presented in the next section. 
The third activity focuses on A to D conversions. Similar to the previous activity, the students step through several screens that explain A to D converters. Then an Excel spreadsheet is launched to illustrate the operation of A to D converters. The students act as the control unit, generating digital values to test. They perform different control algorithms such as count up or successive approximation. This activity helps the students grasp the concept of why it takes longer to perform A to D conversions when there are more bits of resolution. More details about this activity are shown in the following sections.

The fourth activity is for review and recap. It reiterates the important points so the students can better apply what they have learned.

D to A Water Analogy Animation.

In Module 1, Session 3, the students explore the properties of D to A and A to D converters. D to A converters are introduced using water instead of current flow because students have experience with water flowing through different size pipes. An animation activity allows them to turn valves (bits) on or off and view the resulting output flow of water. Five pipes, each with a different diameter, exit the bottom of a tank. The pipes are sized so that their flow corresponds to powers of 2. The setup is shown in Figure 3.

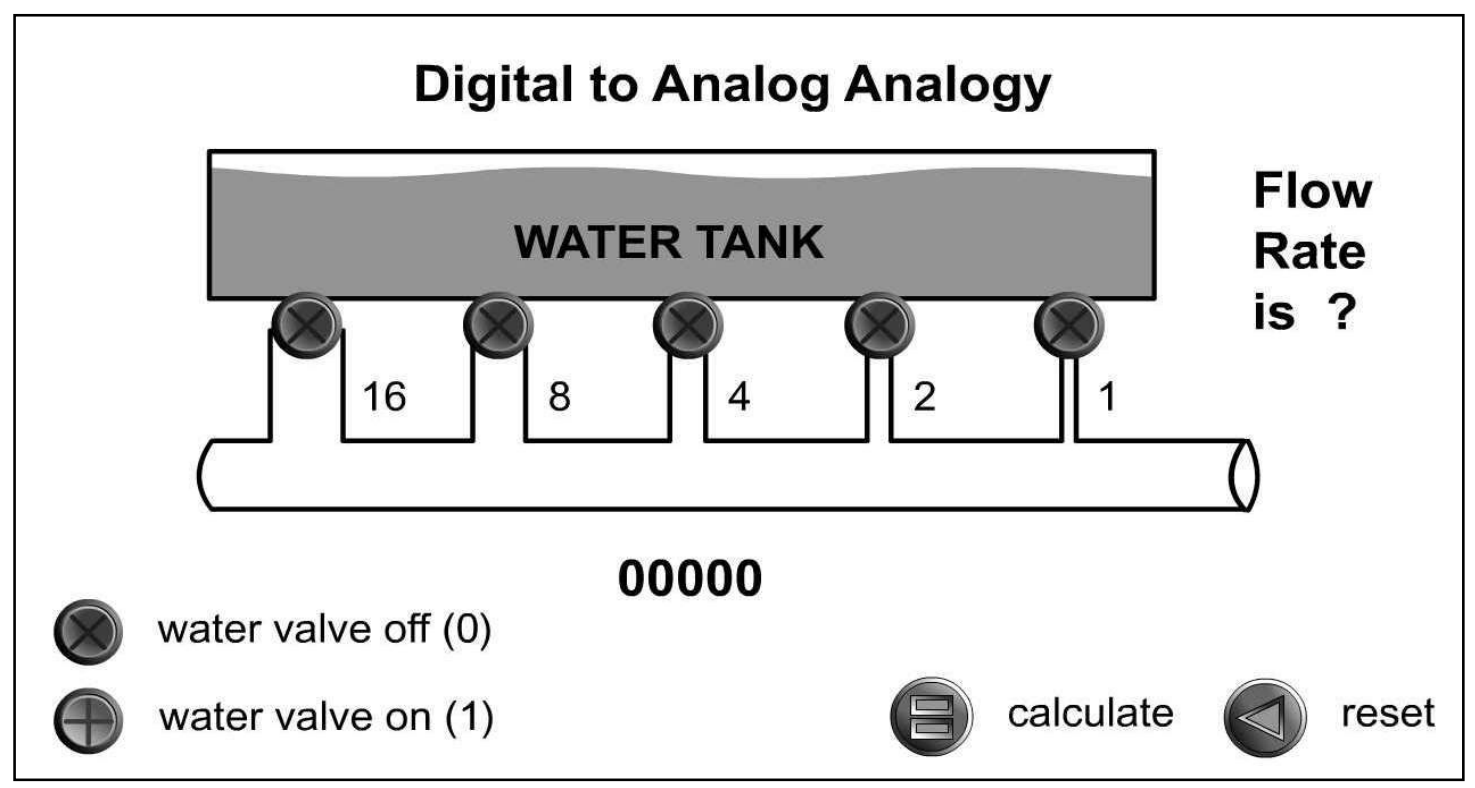

Figure 3. D to A converter with all valves closed.

The student clicks on several valves to open them and then clicks on the "calculate" button. At this point an animation runs showing water flowing through the open valves and out the pipe. The flow of water is proportional to the size of the pipes that are open. Figure 4 shows the screen with the 16, 4, and 2 valves open. The binary number that corresponds to the open valves, 10110, is shown. After the water flow stabilizes, the flow rate of 22 is displayed. 


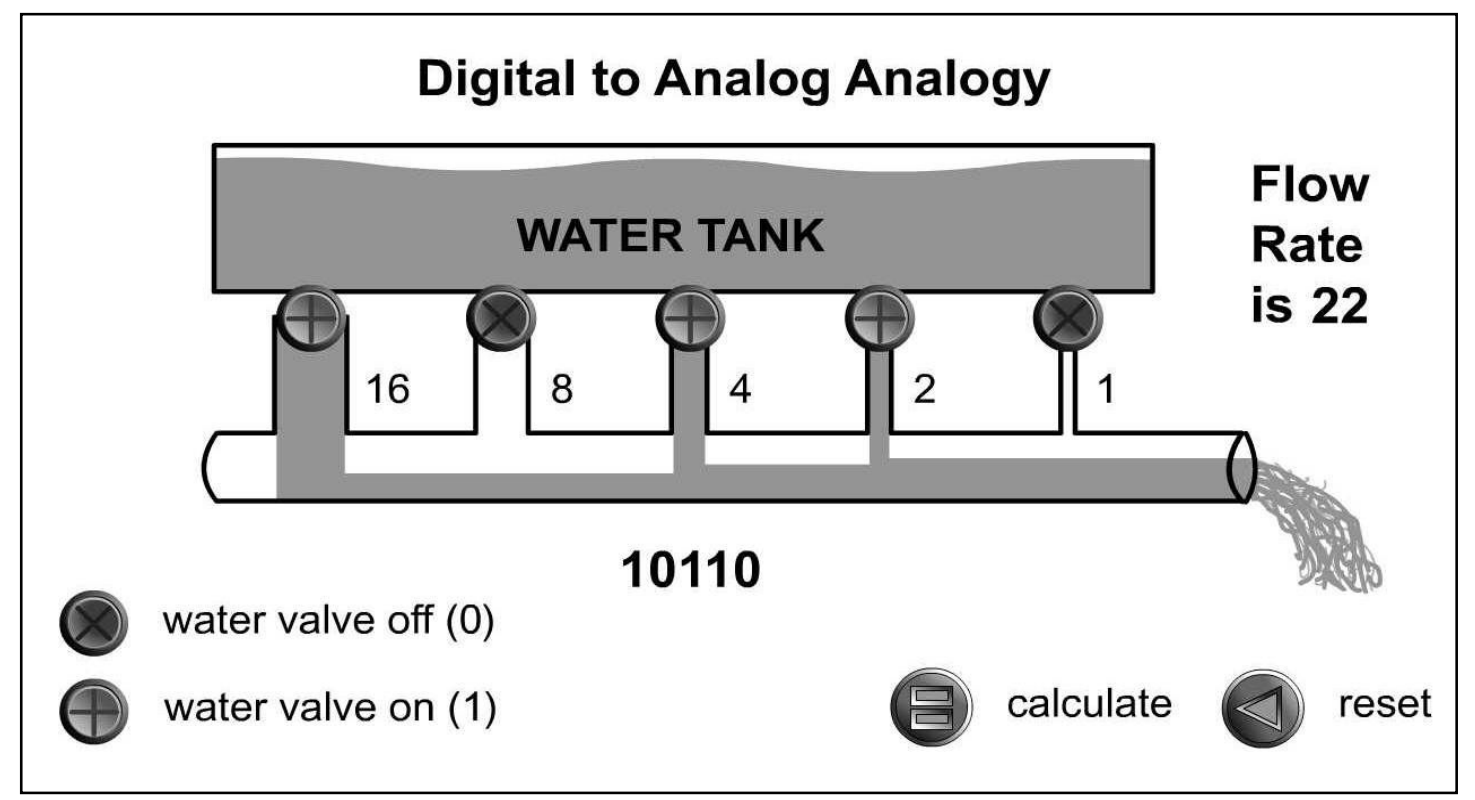

Figure 4. D to A converter with three valves open.

The students work through several examples to better understand the concept. Furthermore, the students can observe how long it takes to achieve a steady-state flow at the output. If additional valves are opened, the time to reach steady state may increase slightly. This point is revisited when $\mathrm{A}$ to $\mathrm{D}$ converters are discussed to show why it takes much longer to perform A to D conversions and why adding extra bits of resolution to an A to D converter significantly increases the conversion time.

A to D Activity using an Excel Spreadsheet

The purpose of this activity is to demonstrate how an A to D converter works using successive approximation. Figure 5 shows a block diagram of an 8-bit converter. The students set the range of the converter using the gray boxes in the lower left corner. Next, they click on the start block in the upper left corner. At this point, the Excel spreadsheet generates a random voltage within the range of the converter. In this example, the range is 0 to 10 volts and Excel generates the voltage 4.17148. At this point, the students become the controller and decide what digital value to test by entering digits in the gray boxes at the bottom of the screen. For this example, successive approximation is used so the high order bit is first set to 1 . As figure 5 shows, the output of the comparator indicates the digital value is too large. The 1 is changed to 0 and the next highest bit is set to 1 . This process continues until all the bits are determined. 


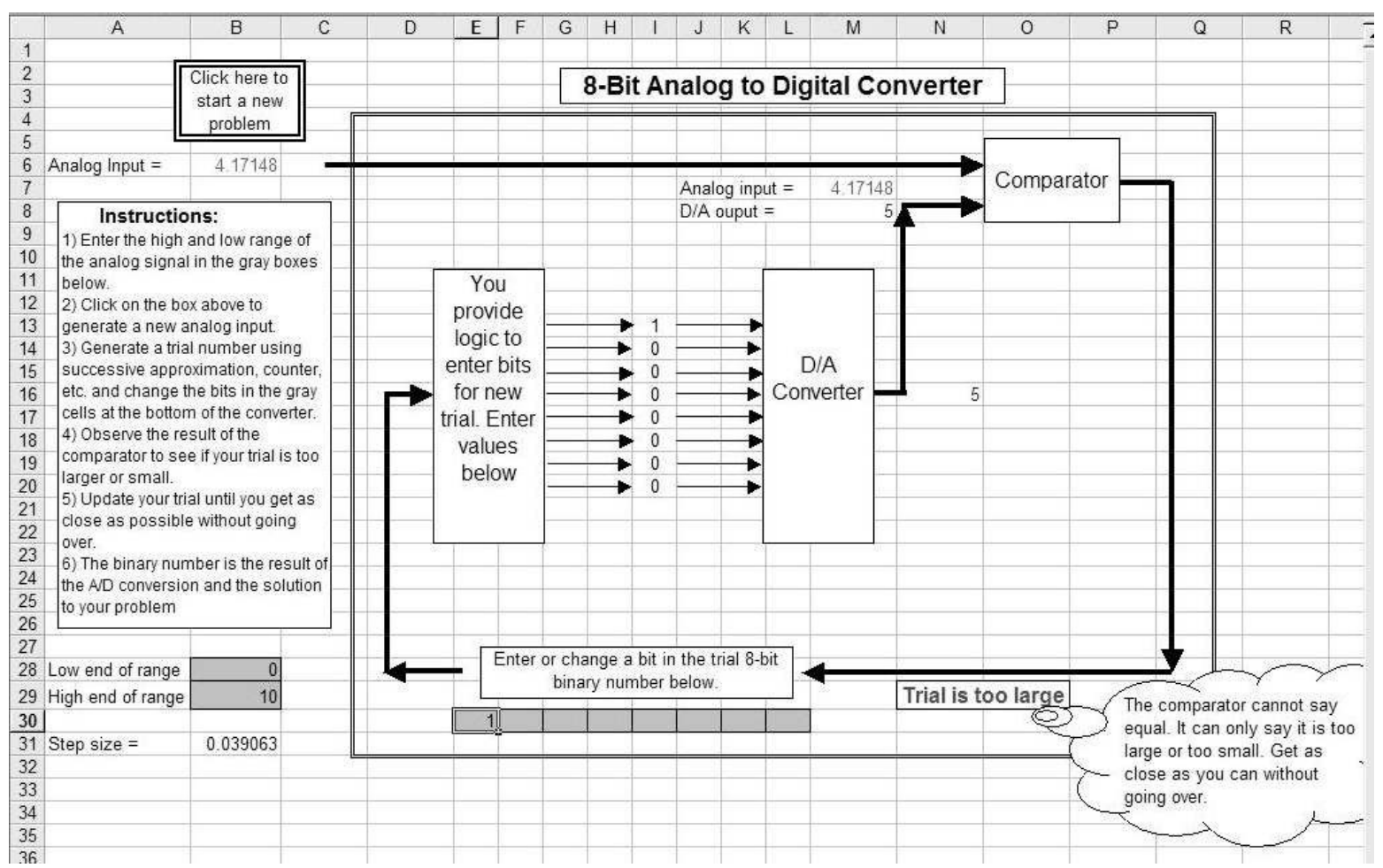

Figure 5. A to D converter at the start of the conversion

Figure 6 shows the result after 4 bits are entered.

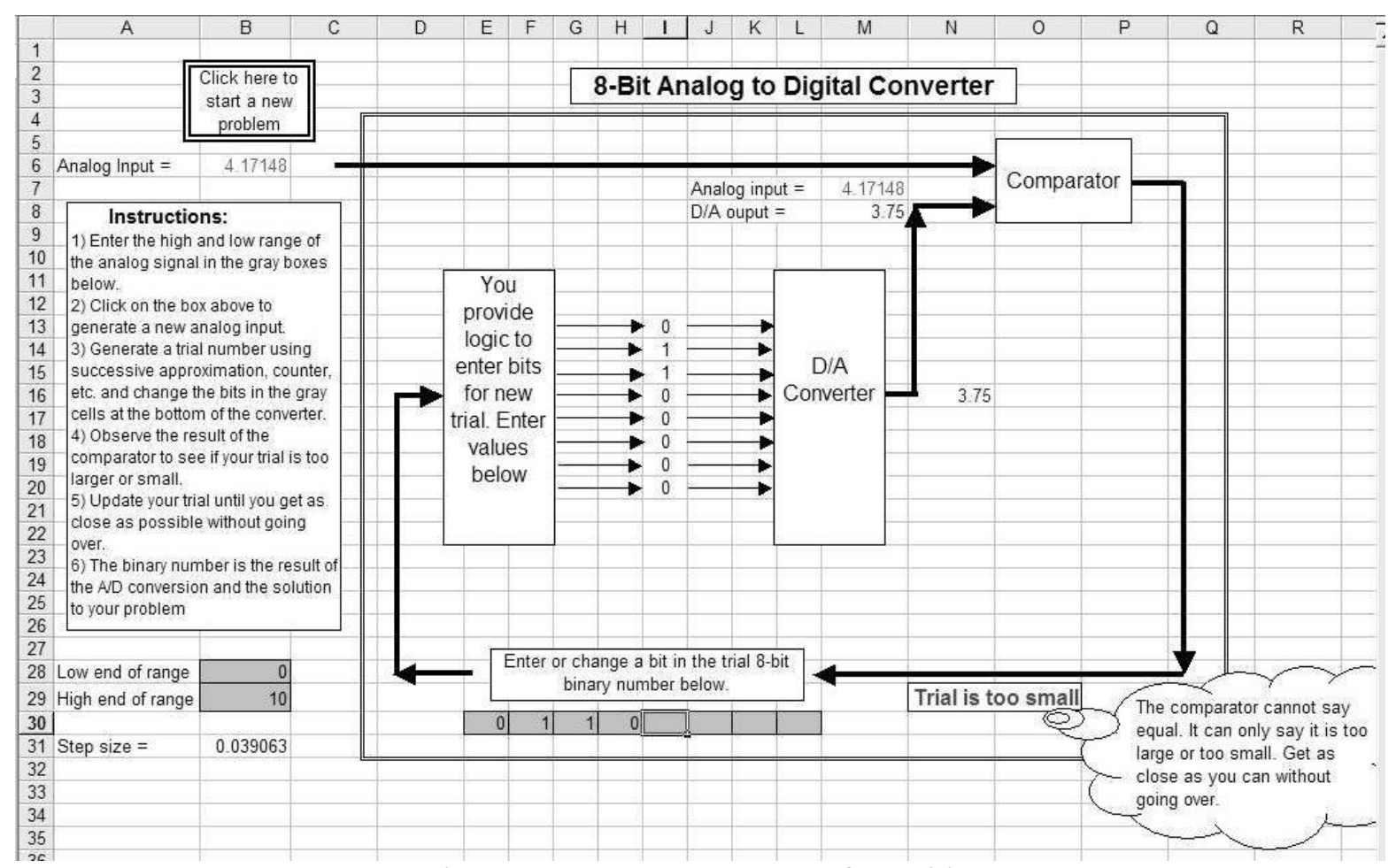

Figure 6 . A to D converter after 4 bits

Proceedings of the 2004 American Society for Engineering Education Annual Conference \& Exposition Copyright $(\mathrm{C}$ 2004, American Society for Engineering Education 
Figure 7 shows the result after all 8 bits have been entered. The D to A output in this figure is very close to the analog value that was randomly generated at the start of the problem.

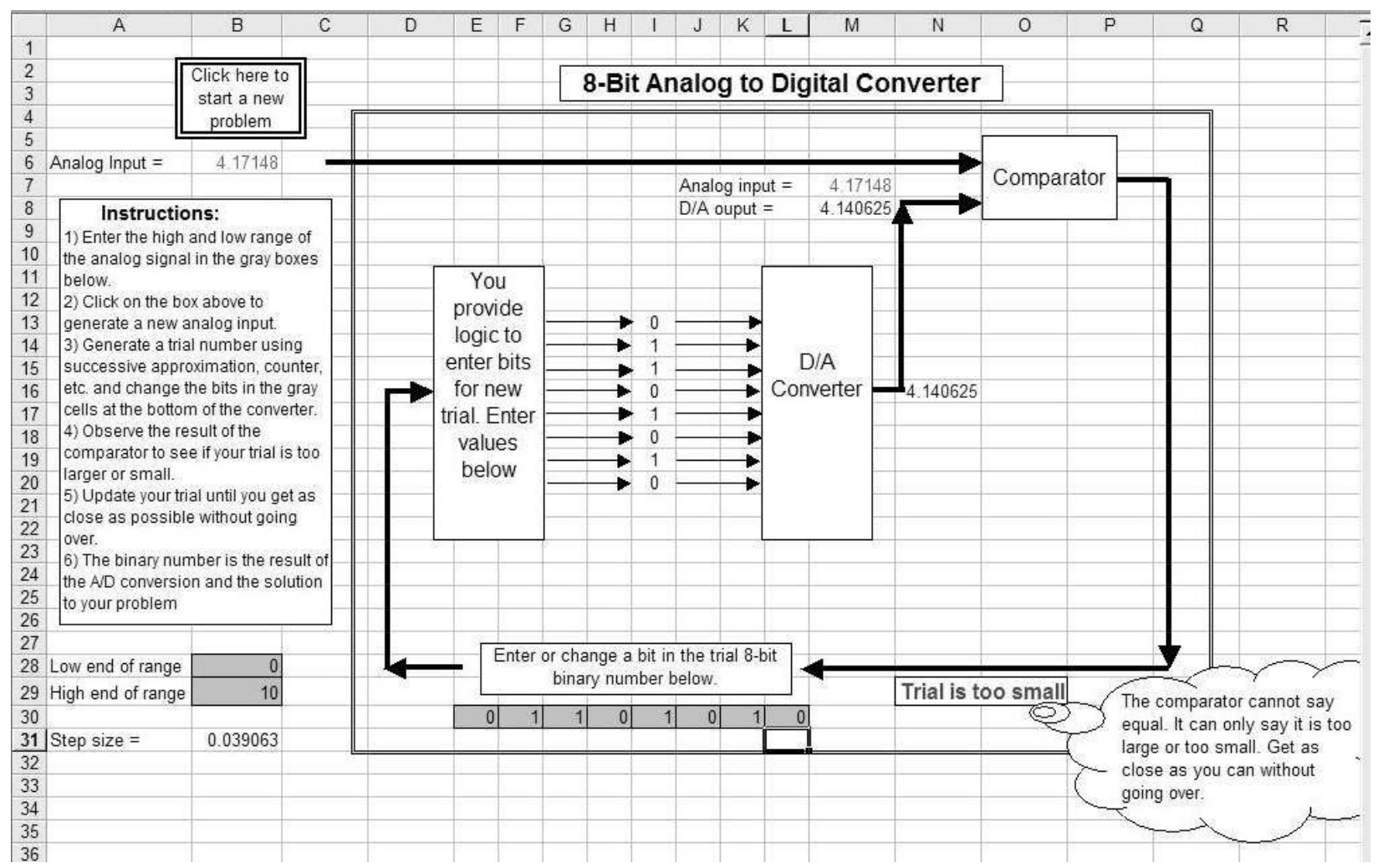

Figure 7. A to D converter after completion

Use of Laboratory Experiments Compared with Simulations

The activities described in the paper are all simulation based in order to allow easy dissemination via the internet. One of the mandates of the National Science Foundation funding is to provide modules and activities that can easily be ported to other universities or environments. Students at Focus: HOPE use their factory experience to provide hands-on activities to reinforce the simulation activities. The hardware and software in the factory provide a rich experience for further study. Lehigh University also offers laboratory experiments where students experience measurements and instrumentation activities.

The simulation and emulation activities developed in these course modules provide an introduction for students to learn before attending the classroom and laboratory sessions. However, for other universities that do not have laboratories in these areas, the simulation activities can provide students with some experience based understanding beyond textboooks.

Conclusion

Measurements and instrumentation are topics usually addressed after students have taken their basic math and science courses. Greenfield Coalition has taken an alternative approach, which introduces students to the topics in their first semesters. The advantage of this approach is that it 
allows students to apply this knowledge to better see the relevance of introductory math and science courses to engineering problems early in their careers. Retention of students in engineering programs is critical in the early years. Many students are lost because they cannot see the applicability of the math and science courses they must take. With introductory courses like Measurements and Instrumentation completed, students can better relate to physics and math when they need to study the topics.

\title{
Acknowledgement
}

Greenfield Coalition is partially supported by Grant EEC-9630951 under the Engineering Education Coalitions Program at the National Science Foundation. Focus: HOPE, the industry partners and academic partners have contributed valuable resources to support the development of Greenfield Coalition.

\author{
Bibliography \\ ${ }^{1}$ Falkenburg, D., "The Greenfield Coalition: Partnership for Change in Manufacturing Engineering and Technology \\ Education," Proceedings of the International Conference on Engineering Education, Oslo, Norway, August 6-10, \\ 2001. \\ ${ }^{2}$ Ahmed, M., Baskin, N., Tonkay, G., Wittchen, A., Zimmers, Jr., E., "Web-Based Learning Activities in \\ Manufacturing Systems," Proceedings of the 2002 American Society for Engineering Education Annual Conference \\ \& Exposition, Montreal, June 16-19, 2002.
}

\section{Biography}

GREGORY L. TONKAY, Ph.D. is an associate professor and associate chairperson of the Industrial and Systems Engineering Department at Lehigh University. He is also the director of the Electronics Manufacturing Laboratory. Tonkay has been actively involved with Greenfield Coalition course and curriculum development since 1994.

EMORY W. ZIMMERS, JR, Ph.D. is Professor of Industrial Systems Engineering and Director of the Enterprise Systems Center at Lehigh University. Zimmers has been responsible for more than 200 funded research and technology transfer projects with over 115 industry and academic partners. He has authored or co-authored one text and over 180 technical reports and publications. He is a Fellow of SME and IIE technical societies.

LAWRENCE R. BUTLER, P.E. is the founder and President of Butler Engineering and Contracting, Inc. An engineering design/build firm that specializes in custom designed machinery, Butler Engineering and Contracting has successfully installed many advanced integrated manufacturing machines and systems throughout the eastern US.

JENNY WANG-CHAVEZ is a project lead and instructional designer at Greenfield Coalition at Focus: HOPE in Detroit, MI. Her work on web-based instruction, group interactions, and integrated instructional strategies has been presented at several national and international conferences such as ISPI, AECT, ED-Media, ASEE and ACEE. 